\title{
Metabolic syndrome definition in adolescents should incorporate insulin resistance
}

\section{Carlos Alberto Nogueira-de- Almeida, MD, MSc, PhD}

Medical Department, Federal University of São Carlos, Ribeirao Preto, SP, Brazil
Received: 5 August, 2020

Accepted: 9 September, 2020

Address for correspondence: Carlos Alberto Nogueira-deAlmeida, MD, MSc, PhD

Medical Department, Federal University of São Carlos, R. Eugenio Ferrante, 170, Ribeirao Preto, SP, CEP 14027-150, Brazil

Tel: +55-16-38775034

E-mail:dr.nogueira@me.com https://orcid.org/0000-0003-12724404
To the editor,

I read Lee et al.'s recent article in the Annals of Pediatric Endocrinology \& Metabolism with great interest. ${ }^{1)}$ The authors demonstrated that the determination of insulin resistance (IR) through age-corrected cutoff points correlates more strongly with metabolic syndrome (MS) than the use of fixed cutoff points. This article is based on another paper published by the same group in $2014^{2)}$ that defined age-adjusted cutoff points for insulinemia and homeostasis model assessment (HOMA) in a Korean population. The approach used was similar to that employed by our research group, in which we defined cutoff points for Brazilian adolescents in a 2008 study $^{3)}$ and sought to validate the data in a 2018 publication. ${ }^{4)}$ Several researchers have demonstrated the importance of using an IR indicator that is simple to obtain and clinically useful when compared to the gold standard, hyperinsulinemic-euglycemic clamp. The use of fasting insulinemia or HOMA may be appropriate, especially if corrected for age and sex, given the presence of a certain degree of physiological IR at puberty. Several groups have sought to define cutoff points appropriate for this purpose and, in parallel, have demonstrated that fasting glycemia is inadequate parameter due to the high compensatory capacity of the young pancreas.

Despite IR being the main etiology of MS, the most widely accepted and used definition of MS from the International Diabetes Federation ${ }^{5)}$ does not use criteria for defining IR, but only places fasting glycemia as one of its diagnostic criteria. The article by Lee et al., ${ }^{1)}$ as well as several others that have been published in recent years, clearly demonstrates that a suitable diagnosis of MS in adolescence needs to take into account IR. Several studies have demonstrated that fasting insulin or HOMA are appropriate indicators for this purpose. The use of fasting glycemia as a criterion can lead to delayed diagnosis of MS among many adolescents, delaying treatment and increasing the risk of early progression to diabetes and cardiovascular disease.

\section{Conflict of interest}

No potential conflict of interest relevant to this article was reported.

\section{References}

1. Lee SH, Ahn MB, Choi YJ, Kim SK, Kim SH, Cho WK, et al. A comparison of different criteria for the definition of insulin resistance and its relationship to metabolic risk in children and adolescents. Ann Pediatr Endocrinol Metab 2020;25:227-33.

2. Yi KH, Hwang JS, Kim EY, Lee SH, Kim DH, Lim JS. Prevalence of insulin resistance and cardiometabolic risk in Korean children and adolescents: a population-based study. Diabetes Res Clin Pract 2014;103:106-13.

3. Nogueira-de-Almeida CA, Pinho AP, Ricco RG, Pepato MT, Brunetti IL. Determination of glycemia and insulinemia and the homeostasis model assessment (HOMA) in schoolchildren and adolescents with normal body mass index. J Pediatr(Rio J) 2008;84:136-40. 
4. Nogueira-de-Almeida CA, de Mello ED. Different criteria for the definition of insulin resistance and its relation with dyslipidemia in overweight and obese children and adolescents. Pediatr Gastroenterol Hepatol Nutr 2018;21:59-67.
5. Zimmet P, Alberti KG, Kaufman F, Tajima N, Silink M, Arslanian S, et al. The metabolic syndrome in children and adolescents - an IDF consensus report. Pediatr Diabetes 2007;8:299-306. 